Jurnal SPORTIF: Jurnal Penelitian Pembelajaran

Vol. 6 No. 1, April 2020, pp. 27-39

doi) https://doi.org/10.29407/js_unpgri.v6i1.13875

\title{
Pengaruh sudut kemiringan raket terhadap pantulan shuttlecock bulu tangkis
}

\section{The relevance of racquet angel and Shuttlecock releasing on badminton}

\section{Bayu Septa Martaviano Triaiditya ${ }^{1}$, Danang Ari Santoso ${ }^{2}$, \& Gatut Rubiono ${ }^{3}$}

\author{
1,2Department of Physical Education, Health and Recreation, Universitas PGRI \\ Banyuwangi, Jl. Ikan Tongkol No. 22, Banyuwangi Regency, East Java Province, 68416, \\ Indonesia \\ ${ }^{3}$ Department of Mechanical Engineering, Universitas PGRI Banyuwangi, Jl. Ikan Tongkol \\ No. 22, Banyuwangi Regency, East Java Province, 68416, Indonesia
}

Received: 7 May 2019; Revised: 4 November 2019; Accepted: 3 March 2020

\begin{abstract}
Abstrak
Pemain bulu tangkis menggunakan berbagai teknik dan strategi dalam permainan. Salah satu tekniknya adalah membangun sudut kemiringan raket yang tepat untuk melepaskan kok. Teknik ini bergantung pada sudut kedatangan shuutlecock yang akan memengaruhi pantulan pada string raket dan lintasan setelah memantul. Penelitian ini bertujuan untuk mendapatkan efek sudut raket terhadap pantulan shuttlecock bulu tangkis. Penelitian ini dilakukan dengan eksperimen memantulkan kok. Jarak awal jatuh bebas bervariasi 100, 125, dan $150 \mathrm{~cm}$. Raket dengan tegangan tali $25 \mathrm{lb}$ diposisikan pada mekanisme penjepitan yang diatur oleh sudut tertentu. Mekanisme ini dipasang di dinding yang dilengkapi dengan pengukur (meteran) untuk mengamati pantulan. Kamera diposisikan 2 meter dari dinding. Pengambilan data dilakukan dengan 5 kali. Data yang ada pada formulir video diubah dalam bentuk foto. Foto-foto ini kemudian dianalisis menggunakan Kinovea 0.8.15. Hasil penelitian menunjukkan bahwa kemiringan sudut raket berdampak pada pelepasan shuttlecock.
\end{abstract}

Kata kunci: bulu tangkis, kemiringan raket, melepaskan kok.

\begin{abstract}
Badminton players use various techniques and strategies in winning the game. One of the techniques is establishing the precise racquet angel for shuttlecock releasing. Hence, this technique relies on the swing of shuttlecock which will affect the bouncing on the racket strings and the way of landing on the other side. This study aims to obtain the relevance of the racquet angle and shuttlecock releasing. The study is conducted with the experiments of shuttlecock bouncing. The initial distance of free fall varies of 100, 125 and $150 \mathrm{~cm}$. The racket with 25 Ib string tension is positioned on the clamping mechanism arranged by definite angle. This mechanism is mounted on the wall which is equipped with a meter to observe the releasing. The camera is positioned 2 meters from the wall. Data is taken 5 times. The data which is in the Video form is altered into photos. These photos are analyzed using Kinovea 0.8.15. The result shows that the inclination of racquet angle has impact on shuttlecock releasing.
\end{abstract}

Keywords: badminton, racquet angel, shuttlecock releasing.

Correspondence author: Bayu Septa Martaviano Triaiditya, Universitas PGRI Banyuwangi, Indonesia. Email: bayusepta7@gmail.com 


\section{PENDAHULUAN}

Bulu tangkis merupakan olahraga yang menggunakan raket dan memukul shuttlecock yang bertujuan untuk mematikan shuttlecock ke daerah lawan. Nomor permainan bulu tangkis yaitu tunggal, berpasangan dan ganda campuran. Peralatan yang digunakan adalah rangkaian bulu yang ditata dalam sepotong gabus sebagai bolanya dan raket sebagai alat pemukulnya, di atas sebidang lapangan. Inti permainannya adalah memasukkan bola di bidang lapangan berukuran panjang 13,40 meter dan lebar 6,10 meter lawan yang dibatasi oleh jaring setinggi 1,55 meter dari permukaan lantai dengan memukulkan raket atas dasar peraturan tertentu (Prastowo, 2015).

Raket bulu tangkis digunakan pada saat permainan sebagai alat untuk memukul shuttlecock menuju lapangan bermain lawan. Bagian raket bulu tangkis terdiri dari pegangan yang terbuat dari kayu dan bahan baku raket terbuat dari campuran serat karbon, grafit, aluminium, dan beberapa perpaduan titanium. Frame terdapat jaring yang terbuat dari senar berupa tali plastik sintetis. Tali raket pada bulu tangkis yang baik adalah senar yang dapat dipasang sekuat mungkin tetapi tidak mudah putus (dengan tarikan 21-24 ukuran ketegangan senar raket) untuk memantulkan shuttlecock dengan cepat dan tepat. Panjang raket yang digunakan dalam permainan bulu tangkis memiliki ukuran standar 66-68 cm dan lebar kepala raket adalah $22 \mathrm{~cm}$. Untuk pegangannya, raket tidak diatur ke ukuran tertentu, ini disesuaikan dengan keinginan pemain (Arnanda, 2017).

Shuttlecock dalam bahasa Indonesia adalah kok dimana bahan kok terbuat dari bulu angsa dan bulu ayam berwarna putih, kok mempunyai panjang 64-16 $\mathrm{mm}$ dan mempunyai diameter $25 \mathrm{~mm}$ berat dari kok untuk permainan bulu tangkis 4,74-295,67 gram. Kok digunakan untuk permainan bulu tangkis dengan cara dipukul kearah lawan. Pada saat permainan berlangsung masing-masing pemain harus berusaha agar shuttlecock tidak menyentuh lantai di daerah permainan sendiri, apabila shuttlecock jatuh di lantai atau menyangkut di net maka permainan 
berhenti (Rahmat 2014). Latihan teknik yang harus dikuasai diantaranya teknik memegang raket, teknik memukul bola, teknik penguasaan kerja kaki (Anugrarista et al., 2013). Teknik memegang raket akan memengaruhi permainan seorang atlet.

Penelitian yang menggunakan raket bulu tangkis sebagai bahan kajian antara lain dilakukan untuk tarikan senar dan kekakuan rangka pegangan (Cross, 2000), modifikasi pegangan raket (Pujianto, 2012), latihan beban raket (Nolosapria, 2014), modifikasi media latihan (Prastowo, 2015), simulasi desain raket (Blomstrand \& Demant, 2017). Penelitian juga dilakukan untuk defleksi raket saat pukulan (Kwan et al. 2010) dan deformasi poros raket sebagai analisis fenomena dinamis gerak smash di bulu tangkis (Koike \& Hashiguchi, 2014).

Pantulan shuttlecock dianalisis untuk pengaruh tarikan dan diameter senar raket bulu tangkis terhadap pantulan shuttlecock (Arianto, et al. 2016a), dan koefisien tumbukan (Nasrudin et al., 2012; Arianto et al., 2016). Arianto et al. (2017) menggunakan lima macam diameter senar berkisar $0.62-0.68 \mathrm{~mm}$, lima tegangan tarikan senar berkisar 22 - $29 \mathrm{lbs}$ dan lima ketinggian jatuh berkisar $100-300 \mathrm{~cm}$ dengan rentang $50 \mathrm{~cm}$. Arianto. et al (2017) menggunakan enam variasi tarikan senar berkisar 22 - 27 lbs, lima diameter senar berkisar $0.62-0.70 \mathrm{~mm}$ dan ketinggian jatuh shuttlecock sebesar $150 \mathrm{~cm}$.

Penelitian gerak shuttlecock sebagai fitur lintasan terbang yang unik (Kaushik, 2017) karena lintasan geraknya berbeda dengan lintasan parabola umumnya (Texier et. al., 2012). Kajian shuttlecock antara lain dilakukan untuk mengetahui ada tidaknya hubungan antara kecepatan dan percepatan (Shibata et. al., 2010), sifat aerodinamis dan perilaku aliran fluida di sekitar shuttlecock yang berputar dengan angka Reynold tinggi (Nakagawa et. al., 2012), sifat rotasi dari bulu shuttlecock (Cao et. al., 2014), efek porositas shuttlecock terhadap hambatan aerodinamis (Alam et. al., 2015), stabilitas shuttlecock sebagai pemodelan dan simulasi respon sudut saat arah balik (Lin et. al., 2015), studi perbandingan reduksi kecepatan shuttlecock bulu dan sintetis saat overhead smash (Rusdiana \& 
Mustari, 2017), dan perilaku shuttlecock dari sudut pandang engineering (Johansson et. al., 2018).

Faktor sudut dalam permainan bulu tangkis telah dikaji antara lain untuk analisis kinematika forehand dan backhand smash mendapatkan sudut raket rata-rata masing-masing sebesar $68.33^{\circ}$ dan $79.00^{\circ}$ (Hussain, 2011). Poros pegangan raket merupakan faktor utama ketika melihat shuttlecock yang akan dipukul dengan memperhatikan sudut raket (Hashimoto \& Toda, 2012). Lintasan shuttlecock sebagai fungsi sudut telah dipelajari secara ekstensif dengan eksperimental, teoritis dan pendekatan numerik (Cohen et al., 2015). Smash dan backhand memiliki pola sudut yang berbeda berdasarkan posisi lengan (Rusydi, et. al. 2015). Sudut pergelangan tangan ditemukan memiliki perbedaan yang signifikan pada sepuluh pemain yang melakukan forehand overhead clear stroke saat fase kontak antara raket dengan shuttlecock (Pandey et. al., 2019).

Dalam permainan bulu tangkis terdapat taktik gerak tipu untuk mengecoh lawan. Gerak tipu merupakan salah satu karakteristik yang penting dalam smash yang berhasil. Hal ini dilakukan dengan mengeksplorasi bidang permainan dan gerakan lawan (El-Gizawy \& Akl, 2014). Sudut serang (angle of stroke) dapat memengaruhi kecepatan dan lintasan shuttlecock (Chen et al., 2009). Gerak tipu dalam pukulan dilakukan dengan memiringkan raket sehingga shuttlecock akan membentuk sudut sesuai dengan arah pantulannya.

Kemiringan sudut raket dalam gerak tipu merupakan sebuah fenomena fisika dimana berlaku hukum dasar pantulan yaitu jika sebuah benda memantul di sebuah permukaan maka sudut datang akan sama dengan sudut pantul. Taktik pukulan dengan kemiringan raket memerlukan kajian untuk mengenali perilaku pantulan shuttlecock. Dengan kajian pantulan ini, maka gerak tipu dalam bulu tangkis dapat dikembangkan lebih lanjut. Desain raket bulu tangkis memerlukan pemahaman aspek pemain, raket, dan interaksi antara pemain dan raket (Gawande et. al., 2017). Berdasarkan uraian latar belakang, maka 
penelitian ini dilakukan untuk mengetahui pengaruh sudut raket terhadap pantulan shuttlecock bulu tangkis.

\section{METODE}

Metode yang digunakan adalah deskriptif kuantitatif dengan pendekatan eksperimen. Shuttlecock dijatuhkan dari ketinggian tertentu ke raket bulu tangkis. Tinggi awal shuttlecock bervariasi antara 100, 125 dan $150 \mathrm{~cm}$ dan sudut inklinasi raket bervariasi antara 0, 10, 20 dan $30^{\circ}$. Rentang tinggi awal dipilih sesuai dengan penelitian Arianto et al., (2016a) dan Arianto et al., (2016b). Ketegangan tali raket dipertahankan 25 pon dengan mengacu pada referensi yang sama. Sudut kemiringan raket dipilih sesuai dengan perkiraan kemiringan yang dilakukan seorang pemain saat melakukan gerak tipu. Gerakan shuttlecock ditangkap dengan kamera. Eksperimen dilakukan dengan lima repetisi untuk kecukupan teknis dalam mendapatkan data rata-rata. Skema percobaan ditunjukkan pada gambar 1 di bawah ini.

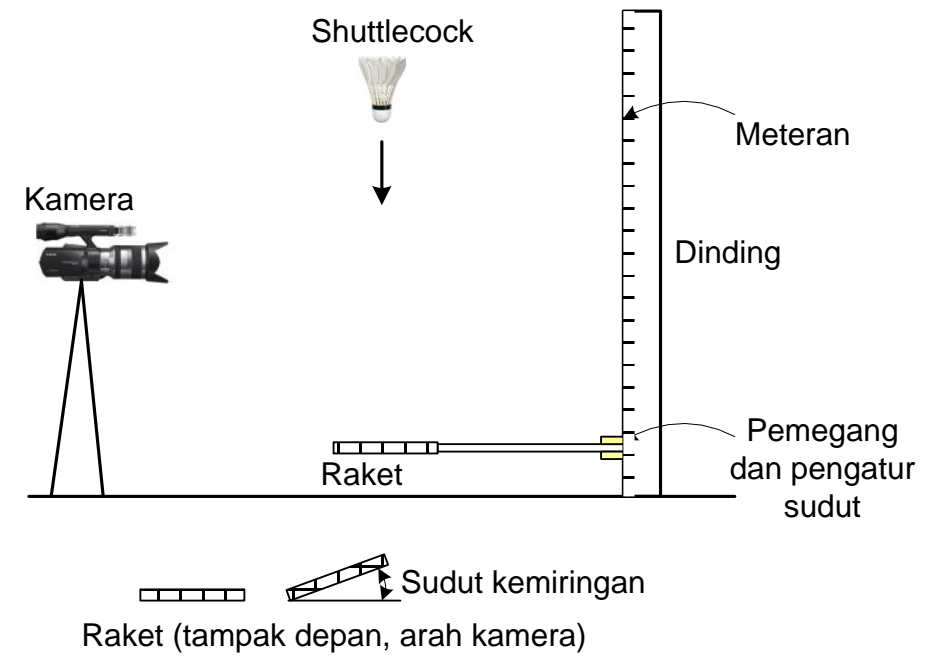

Gambar 1. Skema eksperimen

Tinggi awal shuttlecock dapat digunakan untuk menghitung kecepatan berdasarkan fenomena fisika dasar yaitu gerak jatuh bebas. Dalam hal ini, efek aerodinamika diabaikan. Perhitungan kecepatan shuttlecock dilakukan menggunakan persamaan:

$$
v=\sqrt{2 g h}
$$


Dengan $\mathrm{g}$ adalah konstanta gravitasi $\left(9.81 \mathrm{~m} / \mathrm{dt}^{2}\right)$ dan $\mathrm{h}$ adalah tinggi awal jatuh (m). Dengan tinggi awal 100, 125 dan $150 \mathrm{~cm}$ maka didapat hasil perhitungan kecepatan shuttlecock sebagai berikut:

Tabel 1. Kecepatan Jatuh Shuttlecock (m/dt)

\begin{tabular}{llll}
\hline Tinggi awal (m) & 1.00 & 1.25 & 1.50 \\
\hline Kecepatan $(\mathbf{m} / \mathbf{d t})$ & 4.43 & 4.95 & 5.42 \\
\hline
\end{tabular}

Data rekaman kamera dalam bentuk video diubah dalam bentuk foto-foto. Data kamera berupa rekaman akan diolah menjadi foto dengan metode frame by frame dan selanjutnya dianalisis menggunakan image software Kinovea 0.8.15 untuk menganalisis pantulan yang terjadi. Hasil analisis digunakan untuk mendapatkan tinggi pantulan dan sudut pantulan. Ketinggian pantulan digunakan untuk mendapatkan koefisien restitusi (coefficient of restitusi). Coefficient of Restitusi (COR) adalah suatu koefisien yang bernilai pecahan antara 0 dan 1 yang merupakan rasio besarnya kecepatan relatif sesudah dengan sebelum tumbukan dua buah benda (Arianto, et. Al, 2016; Nasruddin, et. Al, 2012; Nasruddin, 2016):

$$
\operatorname{COR}=\sqrt{\frac{h_{r}}{h_{d}}}
$$

Dengan $h_{r}$ tinggi pantulan (meter) dan $h_{d}$ adalah tinggi awal (meter).

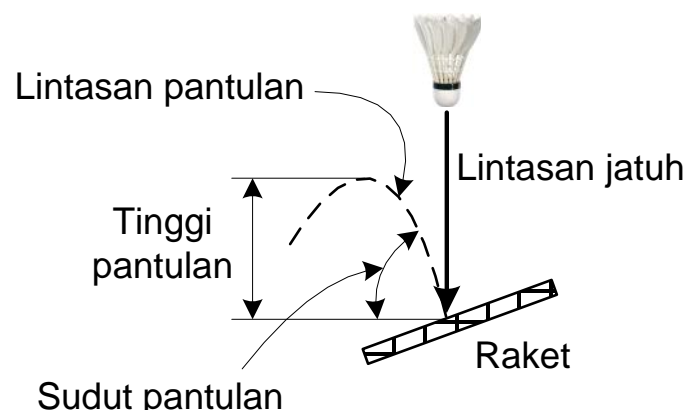

Gambar 2. Skema analisis 


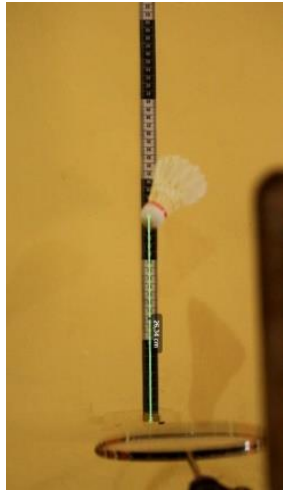

(a)

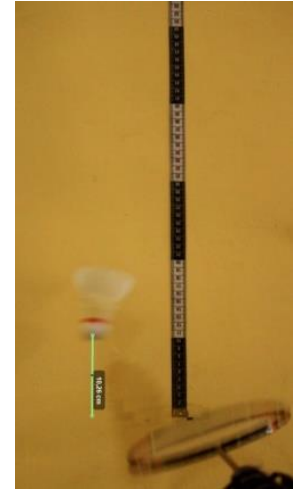

(b)

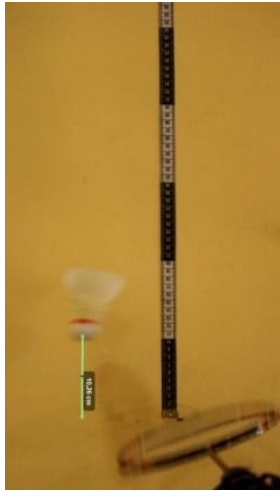

(c)

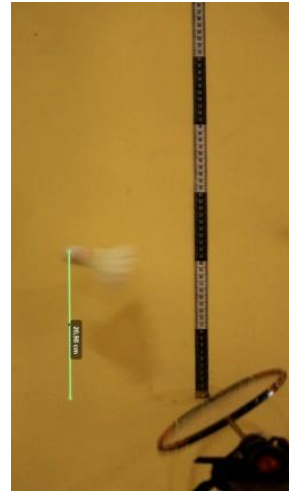

(d)

Gambar 3. Contoh tampilan pantulan

\section{HASIL DAN PEMBAHASAN}

Hasil analisis menggunakan perangkat Kinovea 0.8.15 dan dihitung nilai rata-rata untuk 5 kali pengambilan data didapatkan data tinggi pantulan rata-rata (tabel 2) dan data sudut pantulan rata-rata (tabel 3) sebagai berikut:

Tabel 2. Data tinggi pantulan rata-rata

\begin{tabular}{cccc}
\hline Sudut Raket $\left({ }^{\circ}\right)$ & \multicolumn{3}{c}{ Tinggi Pantulan Rata-rata dengan Tinggi Awal } \\
\cline { 2 - 4 } & $\mathbf{1 0 0} \mathbf{~ c m}$ & $\mathbf{1 2 5} \mathbf{~ c m}$ & $\mathbf{1 5 0} \mathbf{~ c m}$ \\
\hline 0 & 23,52 & 28,65 & 33,09 \\
10 & 23,43 & 28,15 & 32,53 \\
20 & 23,43 & 27,48 & 30,64 \\
30 & 22,86 & 26,26 & 28,70 \\
\hline
\end{tabular}

Tabel 3. Data sudut pantulan rata-rata

\begin{tabular}{|c|c|c|c|}
\hline \multirow[t]{2}{*}{ Sudut Raket $\left({ }^{\circ}\right)$} & \multicolumn{3}{|c|}{ Sudut Pantulan rata-rata $\left({ }^{\circ}\right)$ dengan Tinggi Awal } \\
\hline & $100 \mathrm{~cm}$ & $125 \mathrm{~cm}$ & $150 \mathrm{~cm}$ \\
\hline 0 & 1,08 & 1,13 & 1,17 \\
\hline 10 & 8,68 & 8,87 & 8,58 \\
\hline 20 & 18,15 & 18,47 & 18,66 \\
\hline 30 & 28,19 & 28,26 & 28,47 \\
\hline
\end{tabular}

Data tinggi pantulan rata-rata di tabel 2 digunakan untuk menghitung koefisien tumbukan menggunakan persamaan (2). Hasil perhitungan didapatkan tabel koefisien tumbukan sebagai berikut: 
Tabel 4. Data Koefisien Tumbukan

\begin{tabular}{cccc}
\hline \multirow{2}{*}{ Sudut Raket $\left(^{\circ}\right)$} & \multicolumn{3}{c}{ Koefisien Tumbukan (COR) dengan Tinggi Awal } \\
\cline { 2 - 4 } & $\mathbf{1 0 0} \mathbf{~ c m}$ & $\mathbf{1 2 5} \mathbf{~ m}$ & $\mathbf{1 5 0} \mathbf{~ c m}$ \\
\hline 0 & 0,485 & 0,479 & 0,470 \\
10 & 0,484 & 0,475 & 0,466 \\
20 & 0,484 & 0,469 & 0,452 \\
30 & 0,478 & 0,458 & 0,437 \\
\hline
\end{tabular}

Tabel 3 dan tabel 4 ditampilkan dalam bentuk grafik sebagai berikut:

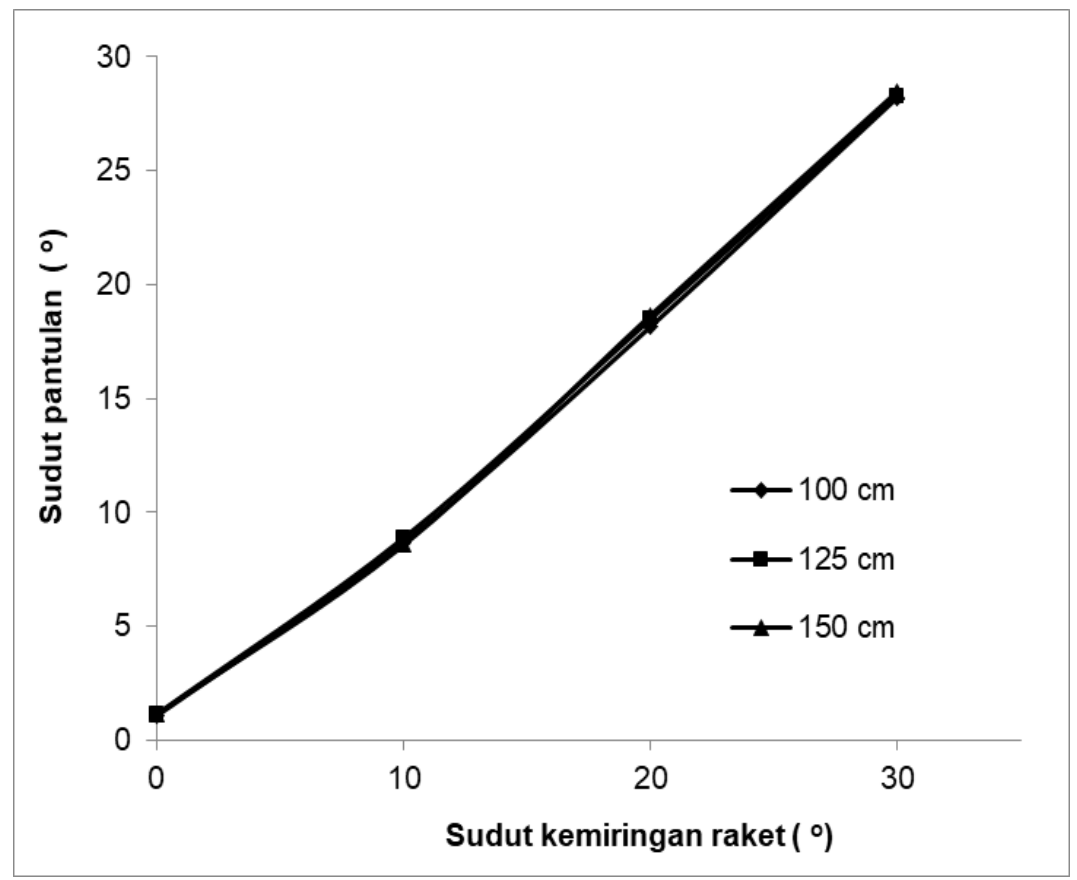

Gambar 4. Grafik hubungan antara sudut kemiringan raket dengan sudut pantulan

Grafik pada gambar 4 menunjukkan bahwa sudut pantulan cenderung memiliki nilai yang sama dengan kemiringan raket. Hal ini dapat dimengerti karena ketika suatu benda yang menabrak atau menumbuk suatu permukaan dengan kemiringan tertentu, benda tersebut akan memantul pada sudut yang sama. Hal ini sesuai dengan hukum pantulan dimana sudut datang akan sama dengan sudut pantul. Data yang diukur dengan Kinovea 08.15 menunjukkan bahwa sudut pantul ratarata berada pada kisaran $87,09 \%$ - 94,35\% dari kemiringan raket. Raket dengan kemiringan $30^{\circ}$ memiliki sudut pantulan maksimum. Prosentase 
didapatkan dengan membandingkan sudut hasil pengukuran dengan sudut kemiringan raket.

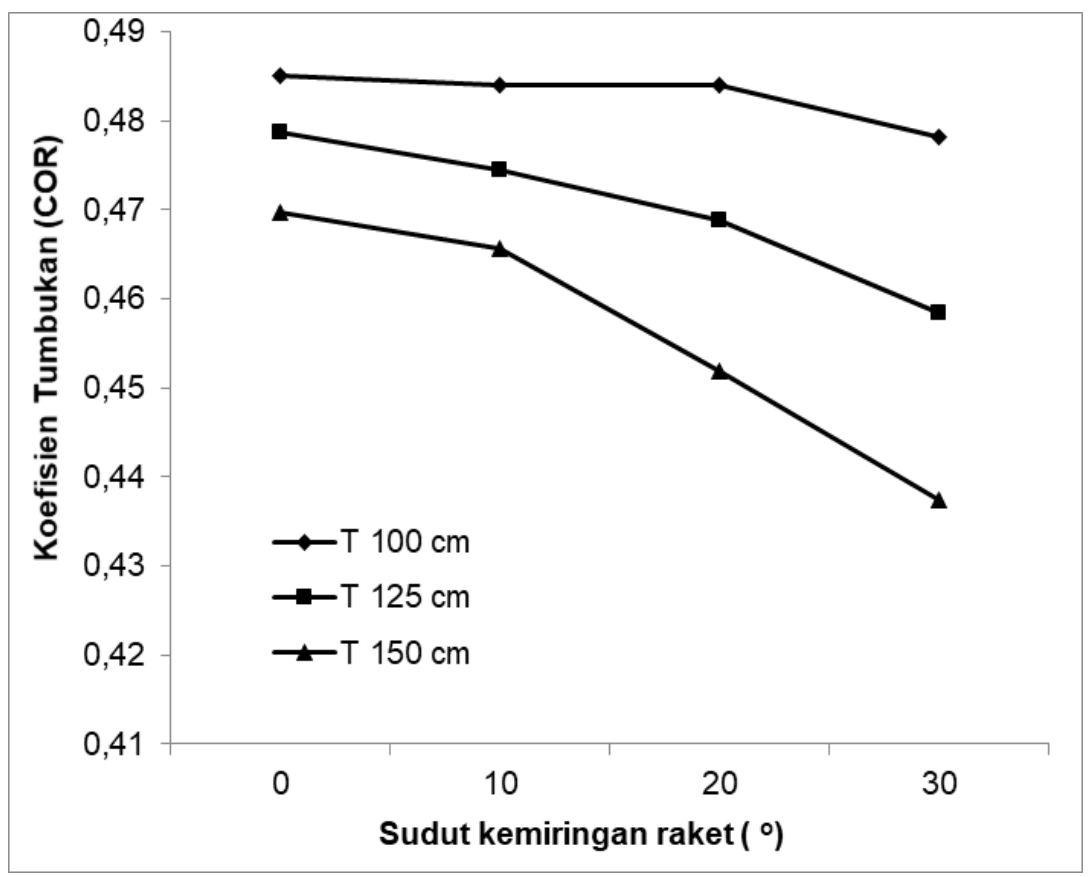

Gambar 5. Grafik hubungan antara kemiringan raket dengan koefisien restitusi (COR)

Grafik pada gambar 5 menunjukkan bahwa koefisien restitusi (COR) cenderung meningkat dengan meningkatnya ketinggian awal. Grafik juga menunjukkan bahwa kemiringan raket cenderung menurunkan nilai koefisien tumbukan. Penurunan COR disebabkan oleh kecenderungan raket yang menurunkan ketinggian pantulan sebagai hasil dari sudut pantulan. Karena kemiringan raket nol, shuttlecock cenderung memantul secara vertikal dan mencapai ketinggian pantulan maksimum. Sudut pantulan menyebabkan tinggi pantulan yang relatif lebih rendah karena belokan yang terjadi saat shuttlecock memantul ketika membentur senar raket.

Data pada tabel 4 diperoleh nilai koefisien restitusi berkisar antara 0.437 sampai dengan 0.485 . Hal ini menunjukkan bahwa tumbukan antara shuttlecock dan senar raket berada dalam kategori tumbukan cukup lenting. Hal ini sesuai dengan kategori tumbukan dimana nilai koefisien 
tumbukan sebesar nol adalah tumbukan tidak lenting, sedangkan nilai koefisien sebesar satu adalah tumbukan lenting.

Hasil pengolahan data menunjukkan bahwa perbedaan sudut kemiringan raket menyebabkan perbedaan sudut pantulan shuttlecock dan tinggi pantulan. Perbedaan tinggi pantulan menyebabkan perbedaan nilai koefisien tumbukan. Secara umum, sudut kemiringan raket berpengaruh terhadap pantulan shuttlecock.

\section{KESIMPULAN}

Sudut kemiringan raket memiliki efek karena pantulan shuttlecock. Pengaruhnya adalah bahwa koefisien tumbukan (COR) cenderung menurun dengan meningkatnya sudut kemiringan raket. Sudut pantulan shuttlecock juga dipengaruhi oleh sudut kemiringan raket. Sudut pantulan cenderung memiliki nilai yang sama dengan sudut kemiringan. Hasil penelitian ini dapat menjadi rekomendasi teknis bagi para pelatih dan pemain dalam mengembangkan olahraga bulu tangkis. Penelitian selanjutnya antara lain dapat dilakukan dengan variasi jenis shuttlecock atau kecepatan awal jatuhnya.

\section{UCAPAN TERIMA KASIH}

Penelitian ini dibiayai oleh Direktorat Riset dan pengabdian masyrakat Direkorat Jendral Penguatan Riset dan PengembanganKementrian Riset, Teknologi, dan Pendidikan Tinggi Sesuai dengan kontrak peneliti Nomor: 113/SP2H/LT/DRPM/2019, tanggal 19 Februari 2019 dengan skim Peneliti Dosen Pemula (PDP). Terima kasih kami sampaikan sehingga penelitian ini berhasil terlaksana dan semoga temuan pada penelitian ini dapat bermanfaat.

\section{REFERENSI}

Alam, F. Nutakom, C., \& Chowdhury, H. (2015). Effect of Porosity of Badminton Shuttlecock on Aerodynamic Drag. Procedia Engineering, 112: 430 - 435.

Anugrarista, E., Atiq, A., \& Supriatna. E. (2013). Pengaruh Pendekatan Keterampilan Taktis Terhadap Ketepatan Smash Bulu tangkis Di SMA Muhammadiyah 1 Kota Pontianak. Artikel Penelitian. Program 
Studi Pendidikan Jasmani Kesehatan dan Rekreasi. Jurusan IImu Keolahragaan. Fakultas Keguruan dan IImu Pendidikan. Universitas Tanjungpura. Pontianak.

Arianto, I. S., Nuri, N., Aji, M. P., \& Sulhadi, S. (2016). Analisis tarikan dan diameter senar raket badminton terhadap pantulan shuttlecock. In PROSIDING SEMINAR NASIONAL FISIKA (E-JOURNAL), 5, 5558.

Arianto, I. S., Nuri, N., \& Yulianto, A. (2017). Effect of the Pull and Diameter String of Badminton Racket Based on Coeffisient of Restitution Value. Journal Of Natural Sciences And Mathematics Research, 2(1), 85-90.

Arnanda, R. D. (2017). Tingkat Pengetahuan Siswa Tentang Permainan Bulu tangkis Kelas X SMK Koperasi Tahun Ajaran 2016/2017 Kota Yogyakarta. Skripsi. Prodi Pendidikan Jasmani Kesehatan dan Rekreasi. Jurusan Pendidikan Olahraga. Fakultas IImu Keolahragaan. Universitas Negeri Yogyakarta.

Blomstrand, E., \& Demant, M. (2017). Simulation of a Badminton Racket, A Parametric Study of Racket Design Parameters Using Finite Element Analysis. Master's thesis. Department of Applied Mechanics. Chalmers University Of Technology.

Cao, X., Qiu, J., Zhang, X., \& Shi, J. (2014). Rotation properties of feather shuttlecocks in motion. Procedia Engineering, 72, 732-737.

Chen, L-M., Pan, Y-H., \& Chen, Y-J. (2009). A Study of Shuttlecock's Trajectory in Badminton. Journal of Sports Science and Medicine, 8: 657-662.

Cohen, C. Texier, B. D., Quéré, D., \& Clanet, C. (2015). The Physics of Badminton. New J. Phys. 17: 1-18.

Cross, R. (2000). Flexible beam analysis of the effects of string tension and frame stiffness on racket performance. Sports Engineering, 3(2), 111-122.

El-Gizawy, H., \& Akl, A-R. (2014). Relationship Between Reaction Time and Deception Type During Smash in Badminton. Journal of Sports Research, 1(3): 49-56.

Gawande, J.S., Pachpore, S. S., \&Kale, S. S. (2017). Failure Investigation of Badminton Racket Using Modal Analysis. International Journal for Scientific Research \& Development, 5(02): 1849-1856.

Hashimoto, T., \& Toda, M. (2012). A Research on Visual Analysis of Badminton for Skill Learning. I.J. Image, Graphics and Signal Processing, (3): 1-7.

Hussain, I. (2011). Kinematical Analysis of Forehand and Backhand Smash in Badminton. Innovative Systems Design and Engineering 2(7): 20-25. 
Johansson, C., Chang, K., Forsgren, C., \& Karlsteen, M. (2018). The Behavior of Badminton Shuttlecocks from an Engineering Point of View. In Multidisciplinary Digital Publishing Institute Proceedings, 2(267), 1-6

Kaushik, V. (2017). Unique Flight Features of Shuttlecock. International Research Journal of Engineering and Technology (IRJET), 4(12): 521-525.

Koike, S., \& Hashiguchi, T. (2014). Dynamic Contribution Analysis of Badminton-Smash-Motion With Consideration of Racket Shaft Deformation (A Model Consisted of Racket-Side Upper Limb and a Racket), Procedia Engineering, 72: 496 - 501.

Kwan, M. Cheng, C-L. Tang, W-T., \& Rasmussen, J. (2010). Measurement of Badminton Racket Deflection During a Stroke. Sports Eng, 12:143-153.

Lin, C. S., Chua, C. K., \& Yeo, J. H. (2016). Badminton shuttlecock stability: Modelling and simulating the angular response of the turnover. Proceedings of the Institution of Mechanical Engineers, Part P: Journal of Sports Engineering and Technology, 230(2), 111120.

Nakagawa, K., Hasegawa, H., Murakami, M., \& Obayashi, S. (2012). Aerodynamic properties and flow behavior for a badminton shuttlecock with spin at high Reynolds numbers. Procedia Engineering, 34, 104-109.

Nasruddin, F.A. Harun, M.N. Syahrom, A. Kadir, M.R.A., \& Omar, A.H. (2012). Coefficient of restitution in badminton racket, Proceeding. iDECON 2012 - International Conference on Design and Concurrent Engineering, Universiti Teknikal Malaysia Melaka (UTeM), 15-16 October 2012.

Nasruddin, F. A., Harun, M. N., Syahrom, A., Kadir, M. R. A., Omar, A. H., \& Öchsner, A. (2016). Coefficient of restitution in badminton racket. In Finite Element Analysis on Badminton Racket Design Parameters (pp. 15-26). Springer, Cham.

Nolosapria. (2014). Pengaruh Latihan Beban Raket Terhadap Hasil Pukulan Long Forehand Dalam Permainan Bulu tangkis Bagi Siswa Kelas VIII SMP Negeri 1 Tungkal Ulu. Artikel Ilmiah. Program Studi Pendidikan Olahraga dan Kesehatan. Fakultas Keguruan dan IImu Pendidikan. Universitas Jambi.

Pandey, B. M., Reddy, T. O., \& Singh, V. (2019). Kinematical Analysis of Forehand Overhead Clear Stroke at the Time of Contact Phase in Badminton. International Journal of Physiology, Nutrition and Physical Education 4(1): 488-490.

Prastowo. (2015). Perbedaan Pengaruh Modifikasi Media Latihan Menggunakan Raket Mini dan Raket Standar Terhadap Hasil Belajar Servis Panjang, Lob, dan Smash Bulu tangkis Usia Anak 
Sekolah Dasar Kelas 5 Sampai dengan Kelas 6 pada Persatuan Bulu tangkis Tri Star Karanganyar. Skripsi. Pendidikan Kepelatihan Olahraga. Fakultas Keguruan dan IImu Pendidikan. Universitas Sebelas Maret. Surakarta.

Pujianto. A. (2012). Modifikasi Pegangan Raket untuk Meningkatkan Kemampuan Teknik Pegangan Bulu tangkis. Jurnal Media IImu Keolahragaan Indonesia, 2(1): 1-8.

Rahmat, A. (2014). Upaya Meningkatkan Hasil Belajar Pukulan Smash Forehand Dalam Permainan Bulu tangkis Melalui Pembelajaran Lempar Bola Atas pada Mahasiswa Kelas A Pagi Semester IV IKIP PGRI Pontianak. Jurnal Pendidikan Olah Raga, 3(2): 105-113.

Rusdiana, A., \& Mustari, A. P. A. (2016). Comparative study of velocity reduction on feather and synthetic shuttlecocks using corrected initial velocity during overhead smash. Journal of Engineering Science and Technology (JESTEC), Special Issue on AASEC, 12, 91-105.

Rusydi, M. I., Sasaki, M., Sucipto, M. H., \& Windasari, N. (2015). Local Euler angle pattern recognition for smash and backhand in badminton based on arm position. Procedia Manufacturing, 3, 898903.

Shibata, M., Amornpatchara, P., \& Sereeyothin, S. (2010). Deceleration of a Shuttlecock. ISB Journal of physics.

Texier, B. D., Cohen, C., Quere, D., \& Claneta, C. (2012). Shuttlecock dynamics. Procedia Engineering, 34, 176-181. 